\title{
Influence of respiratory distress syndrome on body composition after preterm birth
}

\author{
W Tang, D Ridout, Neena Modi
}

\begin{abstract}
Aim-To observe changes in body composition during the first week after birth, in preterm neonates with and without respiratory distress syndrome (RDS), so as to be able to provide optimal fluid and energy intake.

Methods-Twenty four babies with RDS and 19 healthy preterm babies, with gestational ages ranging from 26-36 weeks, were studied daily for the first week after birth. Total body water (TBW) was measured using bioelectrical impedance analysis. The babies were weighed daily and a record made of fluid and energy intake. Body solids were calculated as the difference between body weight and TBW. Results-There was a highly significant reduction in body weight by the end of the week, with the RDS babies losing more than the healthy babies (RDS 7.6\%; nonRDS $3.7 \%$ ). There was no significant difference in the amount of TBW at birth in the babies with and without RDS (RDS $85.1 \%$; non-RDS $85.5 \%$ ) and both groups lost the same amount of body water (RDS $10.9 \%$; non-RDS $9.9 \%$ ) by the end of the first week. The amount of total body water lost was unrelated to the volume of fluid administered. There was a loss of body solids during the first day in the RDS group, but, overall, there was a highly significant increase in both groups between birth and day 7 , which was greater in the healthy babies (RDS $13.0 \%$; non-RDS $42.7 \%$ ).
\end{abstract}

Conclusions-Loss of body water after birth occurs to the same extent in healthy preterm neonates and in babies with RDS and is unrelated to the volume of fluid administered. Given adequate nutritional support, an increase in body solids can accompany early postnatal weight loss and begins almost immediately after birth, in both healthy preterm babies and babies with RDS.

(Arch Dis Child 1997;77:F28-F31)

Keywords: body composition; bioelectrical impedance analysis; total body water; respiratory distress syndrome; nutritional support

There are conflicting data regarding the nature of postnatal weight loss and alterations in body composition in the first week after preterm birth, ${ }^{1-3}$ making it difficult to optimise fluid and nutritional support for sick preterm babies. Earlier studies may no longer be informative, given the substantial changes in neonatal management that have occurred during the past decade.

Estimates of body water content have in the past relied mainly on invasive dilution methods utilising stable isotopes. As a result, each infant could only be studied once or twice in a short period, making ascertainment of changes over a short time span difficult. There have therefore been very few studies assessing longitudinal changes in body composition, in the immediate postnatal period. Assessment using bioelectrical impedance analysis offers a potential way out of these difficulties. ${ }^{4}$

Postnatal fluid balance seems to be an important influence on morbidity in babies with respiratory distress syndrome (RDS)..$^{5-8}$ Preterm neonates are also at high risk of poor growth. The aim of this study was, therefore, to observe changes in body composition during the first week after birth, in preterm neonates with and without RDS.

\section{Methods}

Preterm babies, admitted to the neonatal intensive care units at Queen Charlotte's and Chelsea and Hammersmith Hospitals and without evidence of renal, gastrointestinal, cardiac or hepatic disease, were eligible. The study formed part of a larger investigation of bioelectrical impedance analysis in neonates and was approved by the Research Ethics Committee of the Royal Postgraduate Medical School and Hammersmith Hospitals Trust. Informed parental consent was obtained.

Babies were allocated into one of two groups based on the presence or absence of RDS. The RDS group consisted of preterm babies with RDS, defined as a need for supplemental oxygen in conjunction with characteristic radiographic appearances. The non-RDS group were healthy preterm babies who had no additional oxygen requirement or need for respiratory support, other than at resuscitation, or an $\mathrm{FIO}_{2}$ of no more than 0.4 for less than 24 hours. Daily enteral and parenteral fluid and energy intakes were recorded for each baby. Breast milk was assumed to have an energy content of $67 \mathrm{kcal} / 100 \mathrm{ml}$.

BIOELECTRICAL IMPEDANCE MEASUREMENTS Starting on the first day after birth, daily bioelectrical measurements were made for one week. Bioelectrical resistance $(\mathrm{R})$ was measured at $50 \mathrm{kHz}$, using tetrapolar surface electrodes, placed on the left hand and left ankle, as described before. ${ }^{9}$ Babies were weighed daily by one of the investigators (WT) 
Table 1 Mean (SD) body composition, energy and fluid intake, birth to postnatal day 7, in both groups of babies

\begin{tabular}{lccccc}
\hline & $R D S(n=24)$ & non-RDS $(n=19)$ & Difference in means & $95 \%$ CI of difference & P value \\
\hline \% change in bodyweight & $-7.6(4.4)$ & $-3.7(4.0)$ & 3.9 & $1.4,6.6$ & $<0.01$ \\
Change in body composition & & & & & \\
$\quad(\%)$ & $-3.5(2.8)$ & $-6.5(3.2)$ & -3.0 & $-1.1,-4.8$ & $<0.01$ \\
\% change in TBW & $-10.9(4.2)$ & $-9.9(4.1)$ & 1.0 & $-1.6,3.6$ & 0.45 \\
\% change in body solids & $13.0(20.0)$ & $42.7(40.8)$ & 29.6 & $10.5,48.8$ & $<0.01$ \\
Energy intake (kcal/kg/day) & $68.2(14)$ & $90.9(11)$ & 22.7 & $14.8,30.6$ & $<0.001$ \\
Fluid intake (ml/kg/day) & $133(18.3)$ & $143(10.1)$ & 10.0 & $0.2,19.2$ & 0.045 \\
\hline
\end{tabular}

using electronic scales, accurate to $1 \mathrm{~g}$. Net body weight was obtained by subtracting the weights of any attachments. Foot length (L) was measured at the start of the study, as we have already shown that there is no significant change in foot length over a period up to 10 days.

Total body water (TBW) was derived from the predictive model:

$\mathrm{TBW}=0.016+0.674 \mathrm{wt}-0.038 \mathrm{wt}^{2}+3.84 \mathrm{~L}^{2} / \mathrm{R}$. We have shown that this model accounts for $99.5 \%$ of the variation in TBW and has a $95 \%$ prediction interval of $165 \mathrm{ml} .^{9}$

DATA ANALYSIS

Body solids were calculated as the difference between body weight and TBW. Body composition was defined as TBW as a percentage of body weight. The change in body weight, body composition, TBW and body solids was calculated as the percentage change from the value on day 1. Unless stated otherwise, data were reported as the mean and standard deviation or mean and range. Overall comparisons of changes from birth were performed using the paired Student's $t$ test and comparison of changes between the groups using the two sample $t$ test. Analysis of covariance was used to compare the relation between loss of TBW and volume of fluid administered, between the two groups over the seven day study period.

\section{Results}

Twenty four babies fell into the RDS group and 19 into the non-RDS group. There was no significant difference in birthweight between the groups (mean: RDS group, $1.571 \mathrm{~kg}$ (range 0.458 to 3.100 ); non-RDS group, $1.769 \mathrm{~kg}$ (range 1.195 to 2.270 ); $\mathrm{P}=0.27$ ), but the $\mathrm{RDS}$ babies were of a lower gestational age (mean: RDS group, 30 weeks (range 26 to 36; non-RDS group, 32 weeks (range 28 to 34 ); $\mathrm{P}=0.02)$. Six babies in the RDS group and two in the non-RDS group were below the 10th centile for birthweight.

In the RDS group nine babies were given one dose of surfactant and 11 received two doses. The RDS babies all required oxygen treatment from birth, and 20 required positive pressure ventilation. By day 7, the last day of the study, only three babies remained ventilated. Fourteen more still required oxygen, with a requirement ranging from $23-44 \%$. Seven were breathing without respiratory support, in air. The median duration of mechanical ventilation was four days and median requirement for supplemental oxygen, two days.

Table 1 shows the summary changes in body weight, body composition, TBW, body solids and energy and fluid intake during the study week, for the two groups of babies. Figures 1 to 4 show the daily change in body weight, body composition, TBW and body solids, for each group.

Overall, there was a highly significant reduction in body weight between birth and day 7 $(\mathrm{P}<0.001)$. The RDS group lost significantly more weight than the healthy babies (RDS $7.6 \%$; non-RDS $3.7 \%$ ) (table 1 ). In the RDS group body weight reached a nadir of $8.6 \%$ below birthweight on day 5 and in the non-RDS group, on day 3, at which time it was $5.9 \%$ below birth weight (fig 1 ).

There was no difference in body composition between the two groups at birth. The RDS group had a TBW content of $85.1 \%$ of body weight on the first day and the non-RDS group, $85.5 \%$ (fig 2). Figure 3 shows the pattern of loss of body water in the two groups. By the end of the first week, there was a highly significant loss of total body water $(\mathrm{P}<0.001)$. However, there was no difference in the amount of body water lost by each group (RDS $10.9 \%$; non RDS 9.9\%) (table 1).

There was a significant difference between the groups in the change in body composition

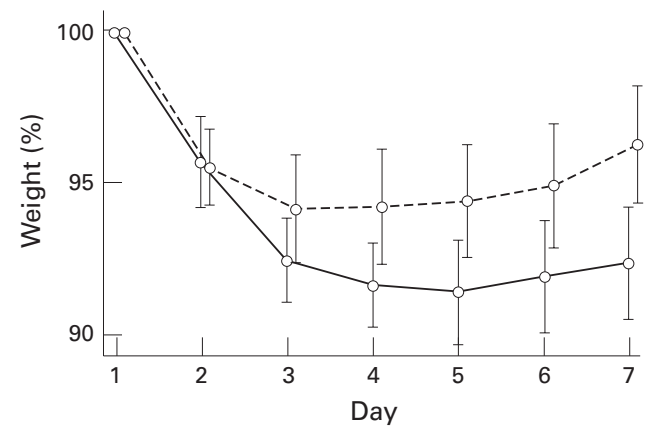

Figure 1 Weight as a percentage of birthweight, days 1 to 7: RDS (solid line) and non-RDS (dotted line) babies; mean $\pm 95 \%$ confidence intervals.

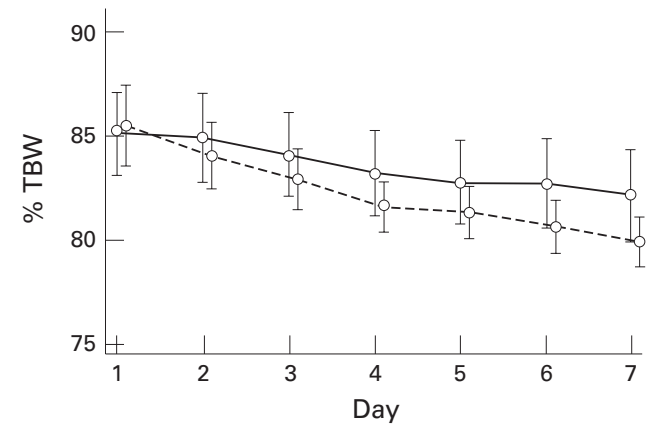

Figure 2 Body composition (total body water as a percentage of body weight), days 1 to 7: RDS (solid line) and non-RDS (dotted line) babies; mean $\pm 95 \%$ confidence intervals. 


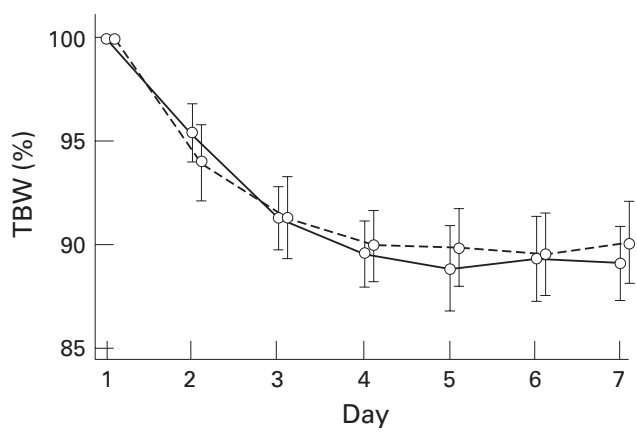

Figure 3 Total body water (TBW) during the first week after birth, as a percentage of TBW on day 1: RDS (solid line) and non-RDS (dotted line) babies; mean $\pm 95 \%$ confidence intervals.

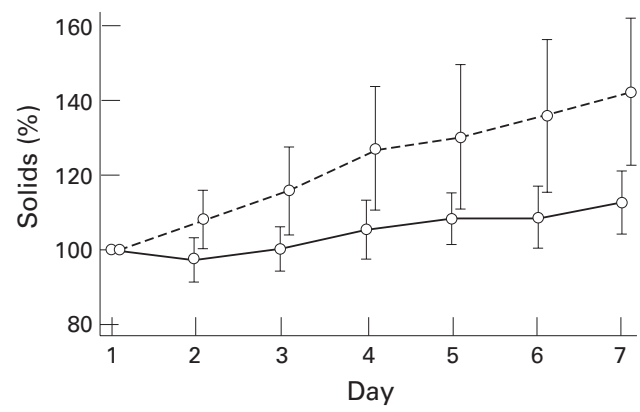

Figure 4 Body solids during the first week after birth, as a percentage of body solids on day 1:RDS (solid line) and non-RDS (dotted line) babies; mean $\pm 95 \%$ confidence intervals.

by day 7 (table 1). This was due to a difference in the change in body solids. There was a loss of body solids during the first day in the RDS group, but thereafter an increase. In the non-RDS babies body solids showed an immediate increase from birth (fig 4). Overall, there was a highly significant increase in body solids between birth and day $7(\mathrm{P}<0.001)$, which was greater in the healthy babies (RDS $13.0 \%$; non-RDS 42.7\%) (table 1).

The healthy, non-RDS group received a highly significantly greater mean energy intake than their sick counterparts, in contrast to only a marginal difference in mean fluid intake (table 1). There was no relation between the volume of fluid administered and loss of body water in individual babies $(\mathrm{P}=0.41)$.

\section{Discussion}

In preterm babies postnatal weight loss has been attributed to both loss of body water and catabolism. ${ }^{1-3}$ Several authors have described a loss of extracellular fluid after birth. In babies with RDS this seems to be delayed and is ultimately marked clinically by the diuresis that accompanies improving respiratory function. ${ }^{10-13}$ It has been recommended that fluid treatment for infants with RDS should be restricted, to promote a postnatal weight loss, and because of concerns regarding the ability of preterm babies with RDS to handle a water load. ${ }^{14}$

The results of the study reported here concur with those of other investigators ${ }^{13} 1516$ in showing an initial loss of body water, but are of particular interest is that both groups lost the same amount of body water by the end of the first postnatal week - around $10 \%$ of the body water content present at birth. This identical loss occurred despite their different clinical status, a highly significant difference in energy intake, and only a marginal difference in fluid intake. Loss of body water was not related to the volume of fluid administered. This supports the view that postnatal body water loss is physiological and occurs in healthy babies as well as in babies with RDS. ${ }^{17}$ Our study also shows that restricting fluid intake in babies with RDS is both unnecessary and detrimental, as restriction of nutritional intake is an inevitable consequence of fluid restriction. Despite concerns about excessive fluid intakes in preterm babies, Coulthard and $\mathrm{Hey}^{18}$ have clearly shown that stable, preterm babies are able to tolerate intakes of $200 \mathrm{ml} / \mathrm{kg}$ from the third day after birth. In this study none of the subjects had extremely severe RDS or went on to develop chronic lung disease, both of which have been associated with a failure to show early loss of body water and loss weight after birth. ${ }^{58}$ This is probably related to an inappropriate early sodium intake rather than excessive fluid volumes. ${ }^{17}$

In this study babies started parenteral nutrition with an amino acid containing solution, during the first 48 hours. Unit policy, with regard to the introduction of enteral feeds, is to aim to start small volumes within the first 48 hours. The preferred feed is either mother's own or bank breast milk. If neither is available a preterm formula is used. Babies receive this combination of parenteral and enteral nutrition with the aim of both optimising energy intake and promoting gastrointestinal tolerance to enteral feeds. The babies with RDS received a smaller energy intake than the healthy babies and although they showed an initial loss of body solids, this was limited to the first day after birth. Thereafter both groups accrued body solids steadily, the non-RDS group to a greater extent than the RDS group. By end of the first week, body solids were $42.7 \%$ greater than at birth in the healthy non-RDS group, in contrast to $13.0 \%$ in the babies with RDS.

This is the first study to show an early increase in body solids in preterm babies with RDS. Van der Wagen et a $l^{19}$ found evidence of catabolism, in babies receiving an energy intake of $47 \mathrm{kcal} / \mathrm{kg} /$ day, during the period of initial weight loss. Bauer et $a l^{15}$, in a study of eight ventilated neonates of median gestational age 28 weeks, receiving an energy intake ranging from $26-57 \mathrm{kcal} / \mathrm{kg} /$ day, found an initial loss of total body water, but no change in body solids during the first two weeks after birth. In a later study, ${ }^{16}$ of 14 appropriately grown infants with a mean gestational age of 31 weeks, eight of whom required ventilation during the first two days after birth, the mean energy intake during the first week was $88 \mathrm{kcal} / \mathrm{kg} /$ day. This energy intake was similar to that in our study, but, unlike us, these authors found no increase in body solids, although there was a significant loss of body water.

Heimler et $a l^{20}$ studied 14 preterm neonates, some of whom were ventilated. Mean 
gestational age was 31 weeks and mean energy intake was $56 \mathrm{kcal} / \mathrm{kg} /$ day. No significant increase in body solids was seen by day 7 . Recently, Singhi et al have shown a $12 \%$ increase in body solids by day 12 , when birthweight was regained. This, however, was in healthy Indian babies between 31-36 weeks gestation, receiving either enteral feeds or intravenous dextrose.

In conclusion, this study has shown that, although a good guide to fluid balance, weight changes in the first days after birth are a poor guide to nutritional management and should not be used as such. There is no difference in the amount of total body water at birth in the babies with and without RDS. Both groups lose an identical amount of body water by the end of the first week, and this is unrelated to the volume of fluid administered.

The study also shows that, given adequate nutritional support, an increase in body solids can accompany early postnatal weight loss and can begin immediately after birth, even in preterm babies. In babies with RDS a mean energy intake of $68 \mathrm{kcal} / \mathrm{kg} /$ day during the first week restricted postnatal catabolism and loss of body solids to a single day. However, the increase in body solids in the healthy babies was significantly greater than in the RDS babies. The cause of this poorer growth performance in babies with RDS is probably a reflection of the reduced energy intake, although differences in energy expenditure might have contributed. ${ }^{21}$ It remains to be seen whether, gastrointestinal and parenteral tolerance permitting, improved energy delivery will permit a pattern of postnatal growth similar to that of healthy preterm babies.

We gratefully acknowledge the invaluable technical expertise of Mr Abdul Dayer and financial support from Action Research.

1 Bauer K, Versmold H. Postnatal weight loss in preterm neonates $<1500 \mathrm{~g}$ is due to isotonic dehydration of the extracellular volume. Acta Paediatr Scand Suppl 1989;360:37-42.

2 Micheli JL, Pfister R, Junod S, Laubscher, Tolsa JF, Schutz $\mathrm{Y}$, Calame A. Water, energy and early postnatal growth in preterm infants. Acta Paediatr Scand Suppl 1994;405:35preter.
3 Singhi S, Sood V, Bhakoo ON, Ganguly NK, Kaur A. Composition of postnatal weight loss and subsequent weight gain in preterm infants. Ind $\mathcal{F}$ Med Res 1995;101:157-62.

4 Gartner A, Sarda P, Dupuy RP, Maire B, Delpeuch F, Rieu D. Bioelectrical impedance analysis in small and appropriate for gestational age newborn infants. Eur $\mathcal{F}$ Clin Nutr 1994; 48:425-32.

5 Brown ER, Stark A, Sosneko I, Lawson EF, Avery ME. Bronchopulmonary dysplasia: possible relationship to pulmonary oedema. F Pediatr 1978;92:982-4.

6 Bell EF, Warburton D, Stonestreet B, Oh W. High volume fluid intake predisposes premature infants to necrotising enterocolitis. Lancet 1979;ii:90.

7 Bell E F, Warburton D, Stonestreet B, Oh W. Effect of fluid administration on the development of symptomatic ductus arteriosis and congestive heart failure in premature infants. N Engl F Med 1980;302:598-604.

8 Van Marter LJ, Leviton A, Allred EN, Pagano M, Kuban KC. Hydration during the first days of life and the risk of bronchopulmonary dysplasia in low birth weight infants. $\mathcal{F}$ Pediatr 1990; 116:942-9.

9 Tang W, Modi N, Price D, Cowan D. Assessment of total body water in neonates receiving intensive care using bioelectrical impedance analysis. Arch Dis Child (in press)

10 Langman CB, Engle WD, Baumgart S, Fox WW, Polin RA. The diuretic phase of respiratory distress syndrome and its relationship to oxygenation. F Pediatr 1981;98:462-6.

11 Heaf DP, Belik J, Spitzer AR, Gewitt MH, Fox WW. Changes in pulmonary function during the diuretic phase of respiratory distress syndrome. F Pediatr 1982;101:1037.

12 Modi N, Hutton JL. The influence of postnatal respiratory adaptation on sodium handling in preterm neonates. Early Hum Dev 1990;21:11-20.

13 Bétrémieux P, Modi N, Hartnoll G, Midgley J. Longitudinal changes in extracellular fluid volume, sodium excretion and atrial natriuretic peptide, in preterm neonates with hyaline membrane disease. Earl Hum Dev 1995;41:221-2.

14 Shaffer SG,Weismann DN. Fluid requirements in the preterm infant. Clin Perinatol 1992; 19:233-50.

15 Bauer K, Bovermann G, Roithmaier A, Gotz M, Prolss A, Versmold HT. Body composition, nutrition and fluid balance during the first two weeks of life in preterm neonates weighing less than 1500 grams. F Pediatr 1991;118:615-20.

16 Bauer K, Cowett RM, Howard GM, vanEpp J, Oh W. Effect of intrauterine growth retardation on postnatal weight change in preterm infants. $\mathcal{F}$ Pediatr 1993;123:301-6.

17 Modi N. Sodium intake and preterm babies. Arch Dis Child 1993; 69:87-91

18 Coulthard MG, Hey EN. Effect of varying water intake on renal function in healthy preterm babies. Arch Dis Child 1985;60:614-20.

19 van der Wagen A, Okken J, Zweens J, Zijlstra WG. Composition of postnatal weight loss and subsequent weight gain in small for dates newborn infants. Acta Paediatr Scand 1985;74:57-61.

20 Heimler R, Doumas BT, Jendrzejczak BM, Nemeth PB, Hoffman RG, Nelin LD. Relationship between nutrition, weight change and fluid compartments in preterm infants during the first week of life. $\mathcal{F}$ Pediatr 1993;122:110-14.

21 Wahlig TM, Georgieff MK. The effect of illness on neonatal metabolism and nutritional management. Clin Perinatol 1995;22:77-96. 